\title{
Reversal learning Improvement in the fish Astronotus ocellatus (Oscar)
}

\section{LESLIE H. SQUIER, Reed College, Portland, Oreg. 97202}

Two Oscars were given over 140 sessions of a simultaneous visual discrimination. Contrary to most reversal studies with fish, between-reversals improvement occurred for both Ss. Spectes and methodological differences may account for this difference in results.

Setterington \& Bishop (1967) reported progressive improvement in successive reversal for the African mouthbreeder, contrasting with the findings of Bitterman (1965). Subsequently, Behrend \& Bitterman (1967) reported no improvement in reversal learning under conditions which the Setterington \& Bishop study indicated should produce improvement. The present study, begun before the Setterington \& Bishop report, was planned to maximize the performance of fish in reversal learning.

Several principles have been identified as important in maximizing fish performance. Hemmings \& Matthews (1963) and Lissmann (1932) both noted that fish confined to small tanks do not perform at maximum levels. Tanks moved to and from an experimental setup subject a fish to vibration and other stimulation which may impair its performance. Some species of fish kept in visual isolation show extreme reactivity to stimuli, to the point of behavioral disorganization. Barlow (1967) demonstrated the usefulness of providing visual access to other fish to reduce or prevent such overreactivity. Changes in illumination greatly affect the activity level of certain fish (Marrone \& Evans, 1966). Target-banging is much easier for some species of fish to acquire than for others. While many reef fish spend hours daily poking at surfaces, Marrone and Evans reported that mouthbreeders were seldom seen to butt or strike an object (contrary to my observations on both adult and fry).

The Oscar has a reputation among hobbyists for trainability and aggressiveness, striking readily at objects. Oscars are claimed to recognize their owners, leap out of water or roll over under water on cue. They are recommended by Hemmings (personal communication) and by Mark \& Davidson (1966) for behavioral and physiological work. Like many cichlids, Oscars exhibit complex social behavior including territorial defense, courtship and mating rituals, and care for eggs and young by both parents, providing excellent Ss for ethological experiments. They are fairly hardy, eat voraciously, and do not require live food. They rarely exceed $1 \mathrm{ft}$ in length in small tanks.

\section{METHOD}

Two Oscars (Astronotus ocellatus), bought locally, nine months of age, $4 \mathrm{in.} \mathrm{long,} \mathrm{were} \mathrm{maintained} \mathrm{on} \mathrm{dry} \mathrm{food} \mathrm{for}$ two months prior to the experiment. $S 1$ was in a 15 -gallon glass tank, S 2 in a 28 gallon tank. Heaters maintained a temperature of $78 \mathrm{deg} F \pm 2 \mathrm{deg}$ and individual filters cleaned the water. The fish discharged so much debris that supplementary cleaning was necessary daily. They grew $50 \%$ in length during the 30 weeks of the studv.

The room was on a 16-h light/8-h dark cycle, and sessions began at least $2 \mathrm{~h}$ after the lights went on. Two clear plastic targets, $1 \frac{1}{4}$ in. in diam, $3 \frac{1}{2}$ in. apart and 4 in. below the water, were mounted on relay contacts which closed mechanically when the fish struck the target. Automatic programming equipment was used. A Davis dispenser dropped $20-\mathrm{mg}$ Noyes fish pellets 1 in. in front of the two targets. The dispenser and targets were mounted on clear plastic tank covers so that the tanks had normal room lighting. One end of the tank was blocked by two in-line projectors on a screen, placed directly in back of the targets before each sesssion. Otherwise, the tanks were unscreened, since screening inhibited target responses. Fish of several species were kept in adjoining tanks during the study. Since sudden changes in light level severely disrupted the Oscars' behavior, no lights-out condition was used.

$A$ white cross on a green field and a white triangle on red were the complex stimuli projected behind the targets, their position changing randomly after each reinforcement. After a correct response, a pellet dropped and a $25-W$ light mounted 6 in. above the tank was lit for 5 sec. The projectors remained on for $1 \mathrm{sec}$ before going off for $5 \mathrm{sec}$. After an incorrect response the projectors turned off at once. Ten seconds later the same positioning of the pattems was presented. A session terminated if no response was made for $10 \mathrm{~min}$ or if more than $2 \mathrm{~h}$ total time elapsed, or if over 300 responses were made before 50 reinforcements occurred.

Each fish received 50 reinforcers per session, usually one session daily, six days a week. Sessions of varying length were used in acquisition, during which $S 1$ gave evidence of satiation on 100 pellets daily. Therefore, reversals were run at the rate of 50 reinforcers daily.

Both fish promptly ate pellets from the dispenser and struck readily at any novel object placed in the tank. There was

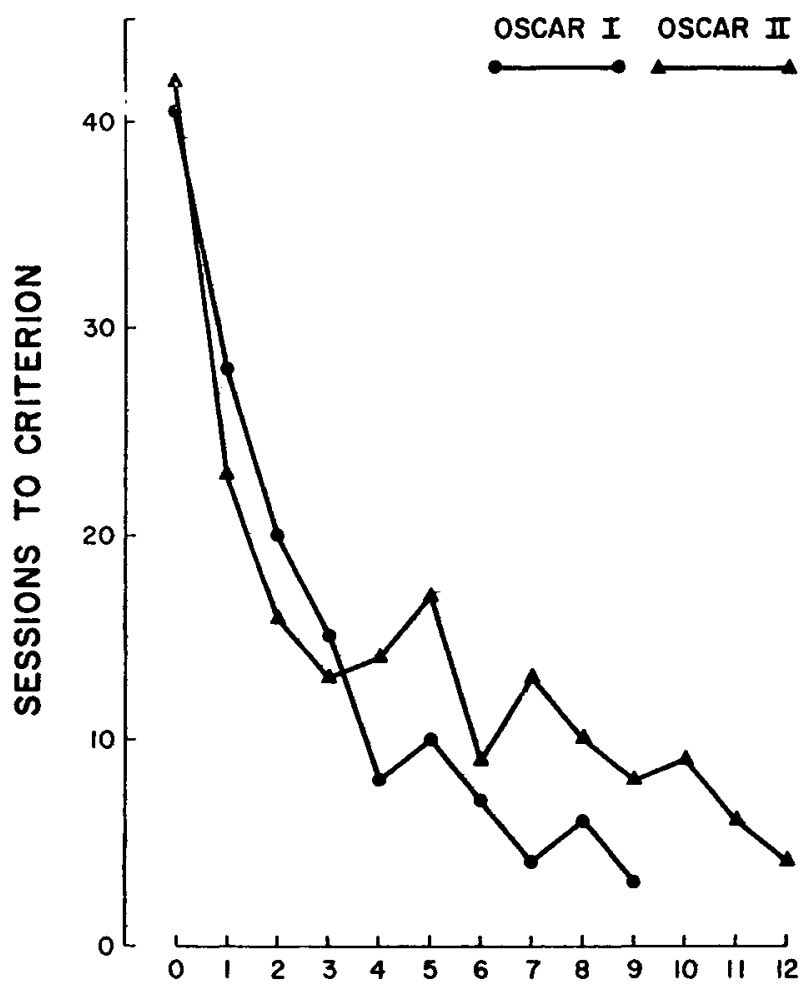

REVERSAL

Fig. 1. Errors to criterion of $96 \%$ in an crigingl white-cross-on-green and white-triangle-on-red discrimination and a series of 12 reversals. Initial errors and repeat errors are indicated sepantely for each of the two Ss. 


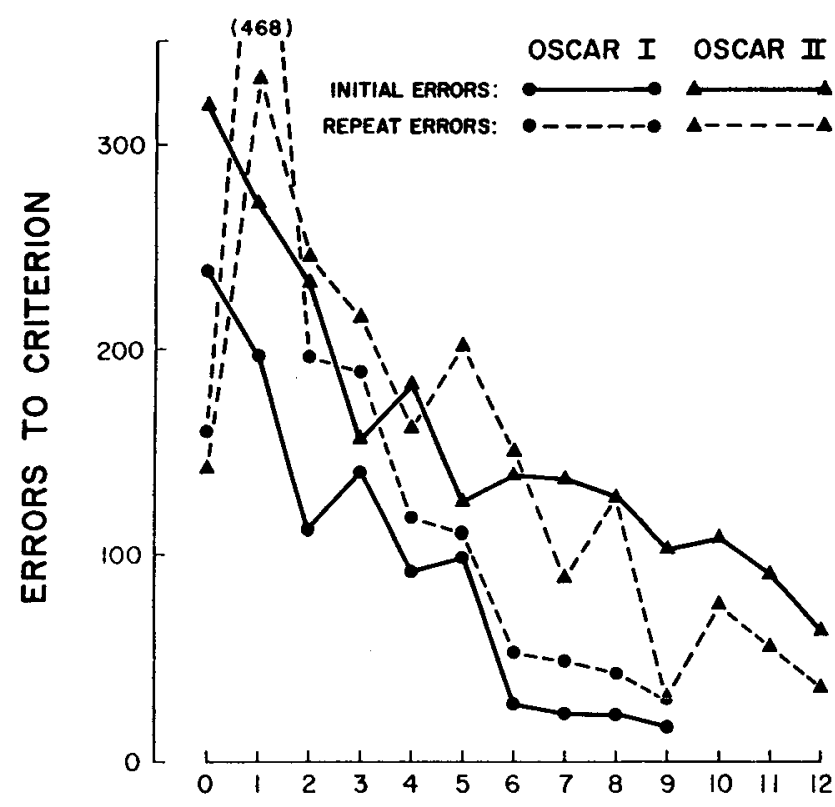

REVERSAL

Fig. 2. Number of sessions required to reach criterion of $96 \%$ for each S. Each reversal session consisted of $\mathbf{5 0}$ correct discriminations, plus errors.

vibration from the feeder, but there was no evidence that it was aversive after the first day. Regular target responding was established in $3 \mathrm{~h}$ without deprivation or shaping. Thereafter, all food was provided in experimental sessions, save for an occasional feeding of angleworms on a nonexperimental day.

A criterion of 96 per cent correct, not more than two errors in $\mathbf{5 0}$ presentations, indicated that the problem was mastered thoroughly before reversal. Both Oscars completed some sessions without error. S1 jumped from its tank despite a glass cover after Reversal 9 and S2 died from an undiagnosed ailment in the midst of Reversal 13.

\section{RESULTS}

Figure 1 shows that both $\mathrm{S} 1$ and S2 steadily improved, making both fewer initial and fewer repetitive errors on later reversals. Fig. 2 shows the number of sessions required to reach criterion by each $S$. Both Ss continued to improve, although neither acquired a correct performance within a few trials, despite the length of the study.

The Oscar may be peculiarly suited to a visual reversal task, producing results superior to other fish species, or, as Setterington \& Bishop (1967) suggest, the Ss may not be representative for their species. Since so few fish species have been used in studies of reversal learning, it is premature to conclude that the Oscar, mouthbreeder, or goldfish is representative of its class (Bitterman, 1965). Mackintosh \& Mackintosh (1964) have shown that cephalopods, evolved in aquatic environments, do improve in reversal learning, so many fish species may have evolved with such potential.

Methodological differences which may account for the differences in results between this and other studies include the use of unscreened tanks with visual access to other fish, constant background of illumination, and large home tanks with no moving of the tank or fish. The use of dry pellets instead of worms as reinforcers is an unlikely cause of the demonstrated improvement, since Oscars do prefer live food.

Clearly, fine-grain analysis of fish behavior in the complex reversal situation is necessary to identify the controlling variables. The improved Ames feeder (1967) and target system (unpublished) will simplify this task, both because of their high reliability and because they permit much more data to be collected per $S$ daily. We are now using this refined equipment.

\section{REFERENCES}

AMES, L. L. A liquid-food, limited-access feeder for fish. Journal of the Experimental Analysis of Behavior, 1967, 10, 435-437.

BEHREND, E. R., \& BITTERMAN, M. E. Further experiments on habit reversal in the fish. Psychonomic Science, 1967, 8, 363-364.

BITTERMAN, M. E. Phyletic differences in learning. American Psychologist, 1965, 20, 396410.

HEMMINGS, G., \& MATTHEWS, W. A. Shape discrimination in tropical fish. Quarterly Journal of Experimental Psychology, 1963, 15, 273-278.

LISSMANN, H. W. Die Umwelt des Kampffishes. Zeitschrift für vergleichende Physiologie, 1932, 18, 62-111.

MACKINTOSH, N. J., \& MACKINTOSH, J. Performance of Octopus over a series of reversals of a simultaneous discrimination. Animal Behavior, 1964, 12, 321-324.

MARK, R. F., \& DAVIDSON, T. M. Unit responses from commissural fibers of optic lobes of fish. Science, 1966, 152, 797-799.

MARRONE, R., \& EVANS, S. Two-choice and three-choice probability learning in fish. Psychonomic Science, 1966, 5, 327-328.

SETTERINGTON, R. G., \& BISHOP, H. E. Habit reversal improvement in the fish. Psychonomic Science, 1967, 7, 41-42.

(Continued from page 142)

simple "thirst" account. Possibly both responses may represent emotional arousal generated by the "frustration" of waiting for small food portions to be doled out at spaced intervals. The primacy of licking may represent the interaction of "thirst" with emotional arousal.

\section{REFERENCES}

FALK J. L. Production of polydipsia in normal rats by an intermittent food schedule. Science, 1961, 133, 195-196.

FALK, J. L. Studies on schedule-induced polydipsia. In M. J. Wayner (Ed.), Thirst. New York: Pergamon Press, 1964. Pp. 95-116.

FALK, J. L. Control of schedule-induced polydipsia: Type, size, and spacing of meals. Journal of the Experimental Analysis of Behavior, 1967, 10, 199-206.

KUTSCHER, C. L. Species differences in the interaction of feeding and drinking. Paper presented at the Conference on Feeding and Drinking, New York Academy of Sciences, February, 1967.

LEVITSKY, D. A. Psychogenic wheel running. Psychonomic Bulletin, 1967, 1, 35. (Abstract)

SCHAEFFER, R. W., \& DIEHL, J. C. Collateral water drinking in rats page 142) on FR food reinforcement schedules. Psychonomic Science, 1966, 4, 257-258.

SCHAEFFER, R. W., \& SALZBERG, C. L. Schedule-induced polydipsia: An aty pical case. Psychological Reports, 1967, 20, 1071-1076.

SEGAL, E. F., \& HOLLOWAY, S. M. Timing behavior in rats with water drinking as a mediator. Science, 1963, 140, 888-889.

SEGAL, E. F., \& ODEN, D. L. Effects of drinkometer current and of foot shock on psychogenic polydipsia. Psychonomic Science, in press.

STELLAR, E., \& HILL, J. H. The rat's rate of drinking as a function of water deprivation. Journal of Comparative \& Physiological Psychology, 1952, 45, 96-102.

STRICKER, E. M., \& ADAIR, E. R. Body fluid balance, taste, and postprandial factors in schedule-induced polydipsia. Journal of Comparative \& Physiological Psychology, 1966, 62, 449-454.

VERPLANCK, W. S., \& HAYES, J. R. Eating and drinking as a function of maintenance schedule. Journal of Comparative \& Physiological Psy chology, 1953, 46, 327-333.

\section{NOTE}

1. This experiment was performed at San Diego State College, and supported by National Science Foundation Grants NSF GB 1605, NSF GB 5777, and NSF GB 7292. I thank William Martin, David Brookshire, and Michael Turner for their assistance in running the experiment. 